"This is the peer reviewed version of the following article: [Journal of Intellectual Disability Research, 2020, 64, (1), pp. 62-67] which has been published in final form at [https://onlinelibrary.wiley.com/doi/abs/10.1111/jir.12694] purposes in accordance with Wiley Terms and Conditions for Self-Archiving." 
Brief Report

Potential for children with intellectual disability to engage in cognitive behaviour therapy: the parent perspective*

\author{
A. Hronis ${ }^{1}$ R. Roberts, ${ }^{2}$ L. Roberts ${ }^{1} \&$ I. Kneebone ${ }^{1}$ \\ ${ }^{1}$ Graduate School of Health, University of Technology Sydney, Ultimo, Australia ${ }^{2}$ The \\ University of Adelaide, Adelaide, Australia
}

* This is the author's version of a work that was accepted for publication in Journal of Intellectual Disability Research. Changes resulting from the publishing process, such as peer review, editing, corrections structural formatting, and other quality control mechanisms may not be reflected in this document. Changes may have been made to this work since it was submitted for publication. A definitive version was published in Journal of Intellectual Disability Research http://hdl.handle.net/10453/142484 
Running head: CBT for children with intellectual disability

\title{
Potential for children with intellectual disability to engage in cognitive behaviour therapy: The parent perspective
}

\begin{abstract}
Background: This study aimed to obtain the opinions of parents and carers of children with intellectual disability (ID) as to whether Cognitive Behaviour Therapy (CBT) could be useful for their children.

Method: A mixed qualitative and quantitative method was employed. Twenty-one carers of children aged 10 to 17 having borderline to moderate intellectual functioning responded to an online questionnaire. Participants were provided with information about CBT and asked to respond to open-ended questions. Quantitative data pertained to questions about their child's ability to identify and describe thoughts, feelings and behaviours. Thematic analysis of responses was conducted using an inductive method of identifying themes from the qualitative data collected.

Results: Five themes emerged from the qualitative analysis: Emotional Attunement (i.e. parent's understanding and recognition of their child's emotions), Role of the Therapist (i.e. ways therapists could facilitate the intervention), Role of the Parent (i.e., ways parents could engage in the therapy process), Anticipated Obstacles (i.e. what may get in the way of the therapy), and Suggested Adaptations for Therapy (i.e. how CBT can be adapted to suit the needs of children with ID). Seventy-six percent agreed that their child would be able to engage in CBT with assistance.
\end{abstract}


Conclusions: The majority of parents believed that CBT is an intervention that children with ID could engage in, provided the therapy is adapted and the therapist accommodates their needs.

Keywords: Intellectual Disability; Learning Disability; Children; Cognitive Behaviour Therapy 


\section{Potential for children with Intellectual Disability to engage in Cognitive Behaviour Therapy: The parent perspective}

\section{Background}

Up to $50 \%$ of children with Intellectual Disability (ID) have a comorbid mental illness (Einfeld et al. 2011; Tonge \& Einfeld 2000). Due to deficits in intellectual functioning, treatments have largely involved behavioural interventions and use of medications (Vereenooghe \& Langdon 2013). Recently, Cognitive Behaviour Therapy (CBT) has been identified as an effective treatment for adults with mild to moderate ID and comorbid depression, anxiety and anger (e.g. Hassiotis et al. 2013; Osugo \& Cooper 2016; Roberts \& Kwan 2018; Vereenooghe \& Langdon 2013). While similar trials have not been conducted among children with ID, CBT could be a treatment option for children with ID, provided adaptations are made (Hronis et al. 2017). Neuropsychological deficits for children with ID have been identified in learning, memory, attention, executive functions and language. The impact on therapy and adaptations for therapy have been proposed specific to CBT (see Hronis et al. 2017).

CBT is the gold standard intervention for many psychopathologies for children without ID (e.g. Cartwright-Hatton et al. 2004; Compton et al. 2004). At the foundation of CBT is the identification and linking of thoughts, emotions and behaviours, which adults with ID can do (Dagnan et al. 2000; Joyce et al. 2006; Oathamshaw \& Haddock 2006; Sams et al. 2006). To our knowledge, this has not been evaluated among children with mild to moderate ID. Parents play a crucial role in the therapy process for children with and without 
developmental disabilities (Manassis et al. 2014; White et al. 2010). Involving parents is in line with family-centred practices for interventions for children, recognising that parenttherapist collaboration in planning and evaluating interventions is key, and based on the principle that parents know their child best (Hanna \& Rodgers, 2002; Rosenbaum et al. 1998).

The aim of this study was to gather the opinions of parents who have children with ID about CBT. The researchers set out to understand if parents who have children with ID believe their child could engage in the process of CBT, and factors associated with this. As to our knowledge, no research has previously investigated this, the study was exploratory.

\section{Method}

\section{Procedure}

This research was approved by the university ethics committee (Approval Number: 2015000482-54). Participants were recruited via online advertising through mental health organisations and social media. The study was advertised as seeking parents/carers of children with a mild to moderate ID, aged 10 to 17 , to respond to questions online about how their child thinks and feels.

\section{Measures}

Parent Report of Child's Ability to Engage in CBT

Participants read information about CBT and rated their child's ability to express feelings, articulate thoughts, describe actions and link thoughts, feelings and behaviours. Parents rated on a five-point Likert scale how often they know if their child is feeling happy, sad, angry and anxious/worried. 
Emotions Development Questionnaire - Parent Form (EDQ-P; Wong et al. 2009)

The EDQ-P assesses emotional understanding, emotional and behavioural regulation, theory of mind and problem solving in children with Autism Spectrum Disorder (ASD), with or without ID (Ratcliffe et al. 2014). Quantitative data was used to supplement qualitative data to describe the emotional development of the sample. It has 29 items rated on a fivepoint Likert scale, added to produce a total score. The EDQ-P has excellent internal consistency ( $\alpha=.91$; Ratcliffe et al. 2014), and was high in the current sample $(\alpha=0.92)$. Higher scores indicate greater emotional understanding.

\section{Open-Ended Questions}

Participants were provided with information about the components of CBT, illustrated by a case example (Supplementary Material A), and responded to open-ended questions about their child's potential to engage in CBT (Supplementary Material B).

\section{Data Analysis}

Descriptive statistics for quantitative data were calculated. Thematic analysis was used to analyze the qualitative data. This involved initial prolonged engagement with the data via repeated readings, coding of responses by two independent researchers, and codes then collated into themes (Braun \& Clarke, 2006).

\section{Results}

\section{Participants}

Participants were 21 parents/carers of children in Australia between the ages of 10 and 17 with a mild or moderate ID, or borderline intellectual functioning. The average age 
was $13.33(S D=2.58)$. Based upon parent reports, $23 \%$ had mild ID, $33 \%$ had moderate ID, $10 \%$ were on the border of mild to moderate ID, $5 \%$ had borderline intellectual functioning, and 29\% were unspecified. Comorbid diagnoses are reported in Table 1.

\section{TABLE 1 HERE}

\section{Quantitative Data}

Most participants reported they could often or almost always tell when their child was sad (76\%), angry (76\%) and happy (72\%). 48\% could often or almost always tell when their child was anxious or worried.

One third agreed that their child can describe their emotional state, while one third disagreed/strongly disagreed and 24\% were undecided (Figure 1). Fourteen percent agreed their child can articulate their thoughts, while $43 \%$ disagreed/strongly disagreed and one third were undecided. Twenty-four percent agreed their child can describe their actions, however $33 \%$ disagreed/strongly disagreed and one third were undecided. Finally, only $10 \%$ agreed that their child could link thoughts, feelings and behaviours, while 19\% were undecided and over half (62\%) disagreed/strongly disagreed. Overall, 76\% agreed that their child would be able to participate in CBT with assistance.

\section{FIGURE 1 HERE}

Seventeen parents completed the EDQ-P, with scores ranging from 80 to 168 out of $200(M=108.1 ; S D=19.9)$, indicating a range of emotional development within the sample.

\section{Qualitative Data}


Length of responses ranged from a few words, to multiple sentences, and were organised into five themes: 1) emotional attunement, 2) role of the parent/carer, 3) role of the therapist, 4) anticipated obstacles, and 5) suggested adaptations to therapy.

\section{Emotional Attunement}

Responses reflected parents' ability to recognise emotional states in their child. Indicators of a child's emotions reported were body language, facial expressions, behaviours, verbal expressions of the emotion, and increased or decreased social interactions.

\section{Role of the Parent/Carer}

Participants referenced taking on the role of the therapist outside of sessions, to help practice and generalise using strategies, as participants stated "I would become the teacher for the therapy and reaffirm therapy at home" and "help with homework". Parents acknowledged they could provide practical support by "sit[ting] in on sessions" and "taking notes". Emotional support they could provide involved encouragement to participate.

\section{Role of the Therapist}

Therapist's knowledge and experience working with children with ID were identified as important. One participant wrote, it would help "if the therapist was understanding of the disabilities my son has and had experience working with them". Parents wanted therapists to understand the strengths and weaknesses of their child and adapt therapy, as one parent stated "the approach taken to engage a child needs to be carefully thought out prior to engagement to reduce the likelihood of shutdown during therapy". 
The difficulty of identifying and expressing thoughts and emotions was identified. Parents questioned whether CBT may be too complex with "too many steps in the process". Rigid thinking was a potential obstacle, as one participant stated their child is " a literal person so won't generalise". Practical obstacles included time constraints, cost of therapy, geographical restrictions, and the difficulty of "finding a clinician willing to work with intellectual disability”.

Suggested Adaptations to Therapy

Parents suggested how CBT could be adapted for their child's needs (Table 2).

TABLE 2 HERE

\section{Discussion}

The involvement of stakeholders is in line with patient-centered care best practices (Epstein \& Street, 2011). To our knowledge, this is the first study exploring the carer perspective about how children with ID can engage in CBT. The results indicate that parents believe their child may benefit from CBT with assistance, provided therapy is adapted for their needs, and barriers to treatment are managed. Although more than half of participants did not think their child could link thoughts, feelings and behaviours, three quarters agreed their child could participate in CBT with assistance. This is promising, because while parents acknowledge their child may not currently have those skills, they are hopeful their child could learn them. Parents provided suggestions on adapting CBT which were consistent with those suggested by Hronis, Roberts and Kneebone (2017). Furthermore, parents were willing to take an active role in treatment, which is beneficial for CBT outcomes (Mendlowitz et al., 1999; Wood et al., 2009). 
A limitation was that parents who responded may be more open to therapy, providing a possible biased sample. Furthermore, the sample size was small, and some participants provided brief responses. Due to the nature of the online questionnaire there was no opportunity to question further. Additionally, formal measures of intellectual and adaptive functioning were not used to confirm diagnoses. Nonetheless, the findings show promise for the use of CBT for children and adolescents with ID and mental health disorders. The results hold important practice implications and can contribute to the development and piloting of adapted CBT programs for children with ID. Future research should focus on experimental studies exploring whether children with ID can make links between thoughts, feelings and behaviours, and research trials evaluating the efficacy of adapted CBT for children with ID. 


\section{References}

Braun V. \& Clarke V. (2006) Using thematic analysis in psychology. Qualitative Research in Psychology 3, 77-101. ISSN 1478-0887.

Cartwright-Hatton S., Roberts C., Chitsabesan P., Fothergill C. \& Harrington R. (2004) Systematic review of the efficacy of cognitive behaviour therapies for childhood and adolescent anxiety disorders. British Journal of Clinical Psychology 43(4), 421-436. doi: $10.1348 / 0144665042388928$

Compton S. N., March J. S., Brent D., Albano A. M. Weersing V. R. \& Curry J. (2004) Cognitive-behavioral psychotherapy for anxiety and depressive disorders in children and adolescents: an evidence-based medicine review. Journal of the American Academy of Child \& Adolescent Psychiatry 43(8), $\quad$ 930-959. doi:10.1097/01.chi.0000127589.57468.bf

Dagnan D., Chadwick P. \& Proudlove J. (2000) Toward an assessment of suitability of people with mental retardation for cognitive therapy. Cognitive Therapy and Research 24(6), 627-636. doi:10.1023/A:1005531226519

Einfeld S. L., Ellis L. A. \& Emerson E. (2011) Comorbidity of intellectual disability and mental disorder in children and adolescents: A systematic review. Journal of Intellectual and Developmental Disability 36(2), 137-143. doi:10.1080/13668250.2011.572548

Epstein, R. M., \& Street, R. L. (2011). The values and value of patient-centered care. Annals of Family Medicine 9(2), 100-103. doi: 10.1370/afm.1239

Hanna, K., \& Rodger, S. (2002). Towards family-centred practice in paediatric occupational therapy: A review of the literature on parent-therapist collaboration. Australian Occupational Therapy Journal 49(1), 14-24. 
Hassiotis A., Serfaty M., Azam K., Strydom A., Blizard R., Romeo R. et al. (2013) Manualised Individual Cognitive Behavioural Therapy for mood disorders in people with mild to moderate intellectual disability: A feasibility randomised controlled trial. Journal of Affective Disorders 151(1), 186-195. doi: 10.1016/j.jad.2013.05.076

Hronis, A., Roberts, L., \& Kneebone, I. I. (2017). A review of cognitive impairments in children with intellectual disabilities: Implications for cognitive behaviour therapy. British Journal of Clinical Psychology, 56(2), 189-207. doi:10.1111/bjc.12133

Joyce T., Globe A. \& Moody C. (2006) Assessment of the component skills for cognitive therapy in adults with intellectual disability. Journal of Applied Research in Intellectual Disabilities 19(1), 17-23. doi:10.1111/j.1468-3148.2005.00287.x

Manassis, K., Lee, T. C., Bennett, K., Zhao, X. Y., Mendlowitz, S., Duda, S., ... \& Bodden, D. (2014). Types of parental involvement in CBT with anxious youth: a preliminary meta-analysis. Journal of Consulting and Clinical Psychology, 82(6), 1163.

Mendlowitz S. L., Manassis K., Bradley S., Scapillato D., Miezitis S. \& Shaw B. E. (1999) Cognitive-behavioral group treatments in childhood anxiety disorders: the role of parental involvement. Journal of the American Academy of Child \& Adolescent Psychiatry 38(10), 1223-1229. doi: 10.1097/00004583-199910000-00010

Oathamshaw S. C. \& Haddock, G. (2006) Do people with intellectual disabilities and psychosis have the cognitive skills required to undertake cognitive behavioural therapy?. Journal of Applied Research in Intellectual Disabilities 19(1), 35-46. doi:10.1111/j.14683148.2005.00284.X

Osugo M., \& Cooper S. A. (2016) Interventions for adults with mild intellectual disabilities and mental ill-health: a systematic review. Journal of Intellectual Disability Research 60(6), 615-622. doi: 10.1111/jir.12285 
Ratcliffe B., Wong M., Dossetor D. \& Hayes S. (2014) Teaching social-emotional skills to school aged children with Autism Spectrum Disorder: A treatment versus control trial in 41 mainstream schools. Research in Autism Spectrum Disorders 8, 1722-1733.

Roberts L. \& Kwan S. (2018) Putting the C into CBT: Cognitive challenging with adults with mild to moderate intellectual disabilities and anxiety disorders. Clinical Psychology \& Psychotherapy. doi: 10.1002/cpp.2196

Rosenbaum, P., King, S., Law, M., King, G., \& Evans, J. (1998). Family-centred service: A conceptual framework and research review. Physical \& Occupational Therapy in Pediatrics 18(1), 1-20.

Sams K., Collins S. \& Reynolds S. (2006) Cognitive therapy abilities in people with learning disabilities. Journal of Applied Research in Intellectual Disabilities 19(1), 25-33. doi:10.1111/j.1468-3148.2006.00303.x

Tonge B. \& Einfeld S. (2000) The trajectory of psychiatric disorders in young people with intellectual disabilities. Australian and New Zealand Journal of Psychiatry 34(1), 8084. doi: 10.1046/j.1440-1614.2000.00695.x

Vereenooghe L. \& Langdon P. E. (2013) Psychological therapies for people with intellectual disabilities: A systematic review and meta-analysis. Research in Developmental Disabilities 34(11), 4085-4102.

White, S. W., Albano, A. M., Johnson, C. R., Kasari, C., Ollendick, T., Klin, A., ... \& Scahill, L. (2010). Development of a cognitive-behavioral intervention program to treat anxiety and social deficits in teens with high-functioning autism. Clinical Child and Family Psychology Review, 13(1), 77-90.

Wood J. J., McLeod B. D., Piacentini J. C. \& Sigman M. (2009) One-year follow-up of family versus child CBT for anxiety disorders: Exploring the roles of child age and parental intrusiveness. Child Psychiatry and Human Development 40(2), 301-316. 
Wong M., Heriot S. \& Lopes A. (2009) The emotions development questionnaire. Sydney, Australia: The Children's Hospital at Westmead. 
Table 1. Rate of comorbid diagnoses in the sample.

\begin{tabular}{l|l|l}
\hline Diagnosis & $n$ & \% \\
\hline Autism Spectrum Disorder & 14 & 67 \\
Attention Deficit Hyperactivity Disorder & 12 & 57 \\
Specific Learning Disorder & 7 & 33 \\
Anxiety & 6 & 29 \\
Oppositional Defiant Disorder & 3 & 14 \\
Depression & 2 & 10 \\
Auditory Processing Disorder & 1 & 5 \\
Cerebral Palsy & 1 & 5 \\
Epilepsy & 1 & 5 \\
Robertsonian Translocation & 1 & 5 \\
Sensory Processing Disorder & 1 & 5 \\
\hline
\end{tabular}


Table 2. Proposed adaptations to CBT by parents of children with ID.

\begin{tabular}{|c|c|}
\hline Adaptations & Specific suggestions from parents \\
\hline Providing Instructions & $\begin{array}{l}\text { - Provide explicit instructions } \\
\text { - Break instructions into small steps } \\
\text { - Use stories to explain concepts and to provide examples } \\
\text { - Use videos to explain and teach } \\
\text { "Teaching in baby steps" } \\
\text { "Make it as simple as possible", }\end{array}$ \\
\hline Prompts and Cues & $\begin{array}{l}\text { "Make a chart of feelings and thoughts so they can visualise } \\
\text { them" } \\
\text { "Behavioural cues to "lock in" lessons" }\end{array}$ \\
\hline $\begin{array}{l}\text { Check } \\
\text { Understanding }\end{array}$ & $\begin{array}{l}\text { - Confirm the child has understood before progressing to the } \\
\text { next step }\end{array}$ \\
\hline
\end{tabular}

"Making sure he understands how to do it before moving onto the next thing"

Practicing Skills $\quad$ Repeat each step multiple times

- Repeat practices of skills

- Practice with multiple examples 
"Getting him to show you"

"Practice in therapy sessions and then practice outside of sessions"

Emotion Training $\quad$ Additional time to be spent on establishing an awareness and understanding of different emotional states

"Teaching children to recognise feelings in the body that occur when getting close to a meltdown"

Support Network

- Have teachers involved in the treatment process

- Have parents involved throughout treatment 
Figure Legend

Figure 1. Parents rating of child's ability for CBT skills. 